\title{
ATLÂNTICO SUL: AS RELAÇÕES DO BRASIL COM OS PAÍSES AFRICANOS NO CAMPO DA SEGURANÇA E DEFESA
}

\author{
Sérgio Luiz Cruz Aguilar ${ }^{1}$
}

\section{Introdução}

Enquanto o Atlântico Sul condicionou o preparo e emprego das forças navais no quadro de defesa das Américas no período da Guerra Fria, hoje essa área se apresenta para a política externa do país como prioridade estratégica e como eixo para a inserção internacional do Brasil. Em consequência, dentro do quadro da chamada cooperação Sul-Sul, que se conformou na década de 1970 e ganhou força no pós Guerra Fria, o Brasil tem firmado uma série de acordos com países africanos, especialmente os localizados na costa ocidental do continente. Além das áreas econômica, política e tecnológica, a cooperação temse dado, também no campo da segurança e defesa.

Dessa forma, o presente trabalho aborda as ações de Cooperação Sul-Sul no campo da segurança e defesa entre o governo brasileiro e os países africanos, em especial os da África Atlântica. Utilizando bibliografia que trata do assunto e fontes documentais, iniciamos com algumas considerações sobre o Atlântico Sul no contexto de segurança e defesa no período da Guerra Fria. Em seguida, abordaremos a cooperação Sul-Sul e discorremos sobre os acordos estabelecidos e os projetos implementados pelo Brasil com os países africanos no período do pós Guerra Fria. Como conclusão, discutimos as dimensões estratégicas dessa cooperação no quadro do fortalecimento das relações políticas do Brasil com

\footnotetext{
${ }^{1}$ Doutor em História (UNESP). Professor do Departamento de Sociologia e Antropologia da UNESP - Campus de Marília/SP. E-m a i l : sergioaguilar@marilia.unesp.br
} 
esses países e da atual reconfiguração das relações internacionais.

\section{O Atlântico Sul no Contexto da Guerra Fria}

Durante a Guerra Fria os países do continente americano viveram sob a ótica da estratégia de contenção praticada pelos Estados Unidos, cujo objetivo era deter o avanço soviético em qualquer lugar que ele se manifestasse. A Junta Interamericana de Defesa, cumprindo com sua função de fazer estudos, emitir recomendações e preparar planos de defesa comum, levantou três hipóteses para a defesa do continente: a primeira em relação à chamada "guerra revolucionária"; a segunda sobre uma "guerra limitada ou intervenção militar consentida, fomentada pelo Grupamento Oriental"; e a terceira sobre "ataque armado do Grupamento Oriental ao Continente, no âmbito de uma guerra geral" (Aguilar 2010, 81).

Delas derivaram as hipóteses de guerra que permearam os planejamentos militares dos países latino-americanos no período: um conflito regional contra algum vizinho; a guerra interna, revolucionária, contra os movimentos de esquerda; e uma guerra extracontinental participando da força aliada comandada pelos Estados Unidos contra as forças do bloco comunista lideradas pela União Soviética (Aguilar 2010, 82).

A terceira hipótese de conflito se inseria na lógica da confrontação global entre as duas superpotências, segundo a qual a segurança da periferia estaria garantida por uma delas. A preparação dos militares latino-americanos para a guerra convencional foi garantido com treinamento nas escolas militares dos EUA e com fonrnecimento de material bélico norte- americano a baixo custo por conta dos programas de auxílio. Como as forças sul-americanas teriam papel fundamental na defesa do Atlântico Sul e do Pacífico, os EUA conceberam e patrocinaram diversas manobras conjuntas com as marinhas do continente.

Embora a marinha dos EUA já tivesse realizado exercícios menores com outras marinhas do continente, como a Operação Neptuno com a Armada Argentina, a primeira grande manobra conjunta com forças navais sulamericanas foi a Operação UNITAS, iniciada em 1959 e realizada até os dias de hoje (Aguilar 2010, 83).

No final da década de 1970, com a possibilidade de aumento da presença da marinha soviética no Atlântico Sul, surgiu a idéia de criar um mecanismo de 
defesa coletiva nos moldes da Organização do Tratado do Atlântico Norte (OTAN) compreendendo Brasil, Argentina, Uruguai e África do Sul, sendo ventilada, também, a presença do Paraguai. No entanto, para o Brasil o Atlântico Sul era prioritário em razão da sua imensa costa e das rotas comerciais marítimas e o governo não percebia uma ameaça que justificasse a criação da chamada Organização do Tratado do Atlântico Sul (OTAS) (Aguilar 2010, 86).

O Ministério da Marinha entendia que a presença naval soviética não seria neutralizada pela união de marinhas do porte das existentes na área; que tal presença não ameaçaria o tráfego marítimo ocidental; a importância da rota que passava pela costa africana derivava do petróleo, rota que, no caso de guerra, seria vulnerável já na sua origem; haveria dificuldades políticas de compor tal mecanismo com a África do Sul, que se encontrava na ocasião isolada politicamente em razão do regime do apartheid. Além do mais, se a intenção da proposta era dificultar a expansão comunista na África, contaria ainda mais com a recusa brasileira que mantinha, naquela ocasião, política de boas relações, especialmente com Angola e Moçambique. A conclusão era a de que tal tratado em nada somaria à segurança dos países envolvidos, seria inócuo pois a força naval dos envolvidos não era compatível com a área a ser defendida, podendo ainda ser prejudicial aos interesses nacionais em relação à África (Aguilar 2010, 86).

Além da UNITAS, outros exercícios multilaterais foram executados por iniciativa norte- americana como as operações Expanded Sea, Ocean Ventura e Export Gold (Aguilar 2010, 152). A operação Oceanic, no início da década de 1980 envolveu unidades navais da América do Sul e sul-africanas (Arquivo Nacional 1981a).

A JID preparou, também, na década de 1960, o Plano para Coordenação do Tráfego Marítimo Interamericano que definiu cinco zonas marítimas, uma delas, abrangendo o Atlântico Sul. Decorrente desse plano, em 1967, foi estabelecida a Área Marítima do Atlântico Sul (AMAS) com o propósito de servir como instrumento de coordenação, treinamento e controle naval do tráfego marítimo. A AMAS compreendia o litoral marítimo do Brasil, Uruguai e Argentina e tinha um Coordenador (CAMAS), função exercida por oficiais dos três países em sistema de rodízio, e um Estado-Maior internacional 
constituído por oficiais desses países e do Paraguai, que também fazia parte da Área. Várias operações foram realizadas pelos Estados Unidos, ou por iniciativa dos integrantes da AMAS, para treinamento de comunicações e adestramento das organizações de controle naval do tráfego marítimo (Arquivo Nacional 1981b, 13).

Além dos exercícios patrocinados pelos Estados Unidos, no final da década de 1960 as marinhas do Brasil e da Argentina iniciaram a realização de operações conjuntas como a Atlantis (exercícios de Estado-Maior Conjunto em guerra de superfície, anti-submarino, antiaérea e eletrônica) que passou a contar também com a participação de meios navais uruguaios. Na década de 1970, a Armada Argentina criou a operação Cimarrón com a Armada do Uruguai (Aguilar 2010, 153).

Na realidade, no contexto da Guerra Fria, o Atlântico Sul em momento algum foi considerado área prioritária sob o ponto de vista estratégico ou geopolítico pelas grandes potências.

Isso facilitou que, em outubro de 1986, a partir de uma proposta brasileira, fosse aprovada pelas Nações Unidas uma resolução estabelecendo Zona de Paz e Cooperação do Atlântico Sul (ZOPACAS) que englobou os três países da costa leste da América do Sul com litoral no Atlântico (Brasil, Argentina e Uruguai), e 21 países da costa oeste da África. Sendo um foro de colaboração e integração regional, os países membros passaram a realizar reuniões periódicas para discussões de problemas comuns (Aguilar 2010, 159).

Com o fim da Guerra Fria, a política externa brasileira procurou adaptar-se a nova ordem global, nas palavras de Bueno e Cervo (2008), adotando uma postura de participação na formulação e aceitação das bases e regras do ordenamento internacional, seus princípios gerais, regimes e procedimentos, ou seja, um modelo que alguns autores chamaram de "autonomia pela participação". A diplomacia brasileira definiu o espaço multilateral como o melhor cenário para a atuação do país no processo de adaptação à nova ordem. Nesse contexto, a cooperação Sul-Sul se conformou como um dos eixos da política externa brasileira, especialmente com os países africanos. 


\section{A Cooperação Sul-Sul}

No sistema internacional contemporâneo, a agenda Norte-Sul dominou as relações entre os Estados e, por conseguinte, os debates no âmbito da Organização das Nações Unidas (ONU).

Na década de 1960, países de independência recente, chamados de subdesenvolvidos ou do $3^{\circ}$ Mundo, passaram a dar mais peso às discussões e participar dos diversos órgãos daquela Organização. A criação do Movimento dos Países não Alinhados (MNA), na conferência de Bandung, foi uma tentativa de vários países de influenciar na agenda global sem estar alinhado com uma das duas grandes potências do período da Guerra Fria. Na década de 1970, esses países buscaram desenvolver laços de solidariedade entre si com o objetivo de compensar, ou diminuir, a dependência histórica em relação às antigas potencias coloniais, fazendo surgir o conceito de cooperação Sul-Sul. Diferente do modelo tradicional Norte-Sul, e relacionado com atraso tecnológico, uma realidade nesses países e o componente essencial da dependência das antigas metrópoles, os esforços foram na direção do estabelecimento da cooperação em bases igualitárias e livre das condicionantes normalmente impostas pelos países do Norte (Nogueira 2010, 1).

Mas a maior parte desses países carecia de instituições políticas sólidas, o desenvolvimento econômico era baixo, as políticas externas insipientes e dependentes das antigas metrópoles, além dos processos violentos que muitos passaram para conseguir e consolidar a independência. Isso fez com que a cooperação se iniciasse timidamente. Com o surgimento e aperfeiçoamento de mecanismos de integração regional e as alterações nos contextos global e interno da maior parte dos países no pós Guerra Fria, a cooperação foi se intensificando.

No caso do Brasil, nos últimos governos, a cooperação com os países do Sul ganhou prioridade na agenda da política externa como forma de inserção internacional do país. Uma das formas de cooperação empregada pelo Brasil é a chamada "cooperação técnica" que consiste no apoio técnico, e não financeiro como ocorre na cooperação tradicional, com o envio de corpo especializado em determinados setores de atuação para capacitar segmentos da população em áreas do conhecimento onde há carência de recursos técnicos.

Os projetos são desenvolvidos por instituições brasileiras ou executados em triangulação com outros países ou organismos internacionais nas mais 
diversas áreas como agricultura, energia, segurança alimentar, meio ambiente, justiça, defesa civil, combate à violência de gênero, saúde, educação, formação profissional, dentre outras, sendo realizada por intermédio da Agência Brasileira de Cooperação (ABC) do Itamaraty (MRE, ABC 2011). A cooperação Sul-Sul é hoje a essência da ABC, foi iniciada com os países africanos e estendida para a América Central, Caribe, Ásia e, em especial, o Timor Leste. Em 2010 a ABC trabalhava em 240 projetos e atividades executadas em 58 países em desenvolvimento (Nogueira 2010, 2).

No caso do desenvolvimento de projetos pelo Brasil, a ABC firma parcerias com instituições que são referência nas suas áreas de atuação como SENAI, SEBRAE, EMBRAPA, FIOCRUZ, dentre outras, e custeia as missões no exterior, enquanto as próprias instituições remuneram seus técnicos colocados à disposição dos projetos. Com isso, os custos são reduzidos (Nogueira $2010,3)$.

A cooperação em triangulação envolve outros países ou instituições, como por exemplo o Banco Mundial. Um exemplo é o projeto de desenvolvimento de satélites denominado CBERS, iniciado com a China na década de 1980, que resultou na construção de satélites de sensoriamento remoto. As imagens obtidas por esses satélites estão sendo compartilhadas com outros países de maneira gratuita. Em 2008, foi lançado pelo Brasil e China o projeto chamado "CBERS for Africa", com o objetivo de ceder imagens para países africanos que poderiam ser utilizadas em áreas como saúde pública, prevenção de desastres, meio ambiente e agricultura (Nogueira 2010,3).

A Cooperação Sul-Sul também se dá por meio de fóruns de consulta e coordenação como o IBAS (Índia - Brasil - África do Sul) que criou um fundo, gerenciado pelo Programa de Desenvolvimento das Nações Unidas (UNDP), que financia projetos de redução da pobreza em vários países, incluindo Guiné Bissau e Cabo Verde, na África. Os projetos do IBAS direcionados para o desenvolvimento econômico são baseados na idéia central da conexão entre estabilidade e desenvolvimento (IBAS, 2012).

A cooperação é executada, ainda, por meio de mecanismos multilaterais como Cúpula América do Sul - África, que simboliza os esforços de cooperação entre blocos de países que desejam adensar o relacionamento político e promover ações de desenvolvimento econômico e social (Nogueira 2010, 6). Nesse campo está incluída a Comunidade dos Países de Língua Portuguesa 
(CPLP), cuja criação e desenvolvimento, fez com que os países da “África portuguesa" como Angola, Cabo Verde, Guiné Bissau, São Tomé e Príncipe e Moçambique, ganhassem prioridade nas ações de cooperação do governo brasileiro.

Dessa forma, a cooperação técnica é atualmente um dos braços da política externa brasileira, "baseada nos princípios de solidariedade e de coresponsabilidade", sem fins lucrativos e desvinculada de interesses comerciais, visando a compartilhar os êxitos e melhores práticas brasileiras "em áreas consideradas mais relevantes pelos próprios países receptores” (Silveira 2002, 285).

Dentre os projetos de cooperação realizados pelo Brasil, vários têm sido estabelecidos no campo da segurança e defesa com países africanos, especialmente os da costa atlântica.

\section{O Atlântico Sul no Contexto Pós-Guerra Fria}

Com o final da Guerra Fria, o papel do Atlântico Sul no contexto da segurança global, como parte da arquitetura de defesa do continente americano, perdeu o sentido que tinha no período anterior. Várias manobras conjuntas continuaram sendo realizadas, patrocinadas pelos EUA ou criadas de maneira bilateral ou multilateral entre Argentina, Brasil e Uruguai. No entanto, tiveram mais o caráter de fomento da confiança mútua que de preparo para lutar contra um inimigo comum.

Os exercícios entre Argentina, Brasil e Uruguai, voltados para o Atlântico Sul ganharam mais força a partir da década de 1990. As marinhas da Argentina e do Brasil criaram operação Araex que incluía o emprego de aviões e helicópteros navais na guerra no mar, com base em exercício semelhante realizado entre as armadas do Uruguai e do Brasil, denominado Uruex. A partir de 2002, os exercícios passaram a reunir as marinhas dos três países. Em 1997, Brasil e Argentina realizaram a Operação Temperex (ações anti-submarinos e de esclarecimentos aéreos), com o porta-aviões brasileiro São Paulo conduzindo aeronaves S-2 $\mathrm{T}$ argentinas ${ }^{2}$. Naquele mesmo ano, os três países realizaram um

\footnotetext{
${ }^{2}$ Na manobra conjunta de 2002, pela primeira vez o novo porta-aviões brasileiro foi empregado em águas jurisdicionais estrangeiras com navios argentinos e uruguaios (Aguilar 2010, 299).
} 
exercício naval, tipo jogo de guerra, denominado Transamérica, versando sobre controle de tráfego marítimo a partir da simulação de uma crise regional em que seria necessária a adoção de medidas para a proteção do trânsito de navios mercantes ${ }^{3}$. As três marinhas criaram, também, um jogo de guerra trilateral de manejo de crises em nível estratégico operacional (Aguilar 2010, 303).

No continente africano, com o final da Guerra Fria, uma série de conflitos movidos pela luta ideológica entre as duas super-potências perdeu o sentido e as fontes de financiamento se encerraram, permitindo a resolução dos mesmos, como os casos de Angola e Moçambique. O fim do regime do apartheid na África do Sul praticamente abriu as portas daquele país para o relacionamento externo e também ajudou no estreitamento dos laços com o Brasil.

Em 1993, a Argentina e a África do Sul criaram o exercício Atlasur, no bojo da ZOPACAS, com foco voltado para ações de superfície, anti-aéreas, antisubmarinas e de guerra eletrônica, sendo testados, também, procedimentos de apoio logístico móvel e aperfeiçoada a interoperabilidade entre os meios navais e aeronavais dos participantes. A partir de 1995, a convite da Argentina, o Brasil e o Uruguai passaram a participar da manobra e oficiais paraguaios estiveram presentes como observadores (Aguilar 2010, 299).

No caso do Brasil, a Política de Defesa Nacional (PDN) aprovada em 2005, incorporou a concepção multidimensional da segurança, bastante discutida no âmbito da Organização dos Estados Americanos (OEA) durante a década de 1990, "abrangendo os campos político, militar, econômico, social, ambiental e outros", mas, manteve a defesa externa como função primordial das Forças Armadas. Dentre as diretrizes estratégicas, apresentou a intensificação do intercâmbio com as Forças Armadas das nações amigas, particularmente com as da América do Sul e as da África, lindeiras ao Atlântico Sul (Brasil. PR 2005).

A PDN apresentou, ainda, que o Brasil participaria em missões de paz e ações humanitárias, de acordo com os interesses nacionais, o que confirmava as ações do governo nesse sentido já a partir do final da década de 1980, onde se

\footnotetext{
${ }^{3}$ O exercício foi ampliado e agregou unidades navais da África do Sul, Argentina, Chile, Colômbia, El Salvador, Equador, EUA, Honduras, Paraguai, Peru, Uruguai e Venezuela (SDM 1997).
} 
enquadra o envio de tropas armadas para as missões de paz da ONU em Angola e Moçambique, em meados da década de 1990. No caso desses dois países, a língua portuguesa e o passado comum como colônia portuguesa, pesaram na decisão de uma maior participação do país nos esforços de paz da ONU. Mas indicava, também, uma maior importância dos assuntos africanos na agenda internacional brasileira.

A Estratégia Nacional de Defesa (END) apresentou que uma das preocupações mais agudas de defesa está no Atlântico Sul. A identificação e a análise dos principais aspectos positivos e das vulnerabilidades levaram a END a determinar uma articulação das forças armadas "capaz de levar em consideração as exigências de cada ambiente operacional, em especial o amazônico e o do Atlântico Sul" (MD, END 2008, 45). A END determinou que, na elaboração das hipóteses de emprego, a Estratégia Militar de Defesa deveria contemplar o emprego das Forças Armadas em decorrência da ameaça de conflito armado no Atlântico Sul. Em consequência, os planos de equipamento e articulação das Forças Armadas deveriam "contemplar uma proposta de distribuição espacial das instalações militares e de quantificação dos meios necessários ao atendimento eficaz das Hipóteses de Emprego", de maneira a possibilitar o aumento da presença militar nas áreas estratégicas do Atlântico Sul e da região amazônica (MD 2008, 49).

$\mathrm{Na}$ conferência de abertura do Seminário Estratégias de Defesa Nacional, em novembro de 2012, o Ministro Celso Amorim levantou a preocupação com as tensões em países da África Ocidental como o Mali e a Guiné Bissau, o narcotráfico associado ao terrorismo e à pirataria marítima, além do risco de se trazerem para o Atlântico Sul "organizações militares com outros propósitos ou visando a outros inimigos ou adversários". Em seguida, afirmou que "o entorno estratégico do Brasil, foco prioritário da lógica da cooperação é composto, de um lado, pela América do Sul, tocando a Antártica, e de outro lado, pelo Atlântico Sul, estendendo-se até a orla ocidental da África" (Amorim 2012, 10).

No mesmo sentido do discurso oficial e dos documentos de defesa, várias ações do governo brasileiro contemplaram os países africanos.

Foram assinados acordos de cooperação no domínio da defesa com Cabo Verde (MRE 1994b), em 1994, a África do Sul (MRE 2003), em 2003, Guiné 
Bissau (MRE 2006), em 2006, com Moçambique (MRE 2009b) e Namíbia (MRE 2009a), em 2009, Nigéria (MRE 2010c), Senegal (MRE 2010d), Angola (MRE 2010a) e Guiné Equatorial (MRE 2010b), em 2010.

Em linhas gerais, se destinavam a: promover a cooperação nas áreas de pesquisa e desenvolvimento, apoio logístico e aquisição de produtos e serviços de defesa; partilhar conhecimentos e experiências adquiridas no campo de operações, na utilização de equipamento militar de origem nacional e estrangeira, bem como no cumprimento de operações internacionais de manutenção de paz; partilhar conhecimentos nas áreas da ciência e tecnologia promover ações conjuntas de treinamento e instrução militar, exercícios militares combinados, bem como a correspondente troca de informação; e colaborar em assuntos relacionados a equipamento e sistemas militares. A cooperação se realizaria por meio de visitas de delegações de alto nível; reuniões entre as instituições de defesa; intercâmbio de instrutores e estudantes de instituições militares; participação em cursos teóricos e práticos, estágios, seminários, conferências, debates e simpósios realizados em entidades militares, bem como em entidades civis de interesse para a defesa; visitas de navios de guerra e aeronaves militares; eventos culturais e desportivos; facilitação das iniciativas comerciais relacionadas a materiais e serviços vinculados à área de defesa; e implementação e desenvolvimento de programas e projetos de aplicação de tecnología de defesa, com a possibilidade de participação de entidades militares e civis de interesse estratégico para as partes.

Em 2004, sob a égide do Acordo Geral de Cooperação que havia sido assinado em 1981, Brasil e Moçambique realizaram um ajuste complementar relacionado com segurança pública. A cooperação nesse campo implicou na coordenação de estratégias e troca de informações sobre programas nacionais referentes à prevenção e combate ao crime; cooperação técnica orientada pela experiência brasileira da implantação do Sistema Único de Segurança Pública; ações de formação de pessoal, em especial, ações de capacitação de docentes e formação de formadores, de cooperação no domínio de implantação dos sistemas de gestão do conhecimento e informações, de estatísticas, de pesquisas aplicadas, e de elaboração de diagnósticos de segurança pública e justiça criminal; e realização de estudos visando à modernização da área de gestão das instituições de segurança pública. A Secretaria Nacional de Segurança Pública do Ministério da Justiça do Brasil ficou responsável pela execução das ações e a 
ABC como responsável pela coordenação, acompanhamento e avaliação das ações (MRE 2004a).

Em 2009, um Ajuste Complementar ao Acordo Básico de Cooperação Técnica e Científica que existia entre o Brasil e a Guiné-Bissau, de 1978, previu a implementação de um Centro de Formação das Forças de Segurança naquele país, com o objetivo de contribuir para a reestruturação e modernização do setor de segurança e defesa, ficando a Polícia Federal brasileira responsável pelas ações decorrentes do ajuste (MRE 2009c).

Em 2010, uma das áreas da parceria estratégica firmada com Angola foi a de segurança pública e defesa. As diretrizes, nesse domínio, apresentaram o estímulo à cooperação entre os ministérios da defesa e os órgãos de segurança pública e a manutenção de "consultas regulares sobre temas bilaterais, regionais e multilaterais", incluindo as iniciativas no âmbito da Zona de Paz e Cooperação no Atlântico Sul e a "cooperação para a solução de conflitos na África e em outras regiões, inclusive construção da paz em situações pósconflito". No campo da cooperação técnica, científica e tecnológica, a parceria contemplou ações para o desenvolvimento de recursos humanos e pesquisas conjuntas nas áreas da indústria naval, segurança pública e defesa. Foi, ainda, estabelecida uma Comissão Bilateral de Alto Nível para "coordenar, acompanhar, avaliar, orientar e assegurar a implementação da parceria" (MRE 2010e).

Dos países da costa atlântica africana, a Namíbia se firmou como a maior receptora da cooperação brasileira no campo da segurança e defesa. Em 1994, o Acordo Naval assinado entre os dois países deu início ao relacionamento entre as marinhas dos dois países com o objetivo "criar e fortificar a Ala Naval do Ministério da Defesa da Namíbia". Todas as despesas de translado e estadia no Brasil, bem como dos militares brasileiros que ficariam naquele país como oficiais de ligação, ficaram a cargo do então Ministério da Marinha brasileiro (MRE 1994a). Na época, foram disponibilizadas vagas para formação de oficiais e praças daquele país nas escolas navais brasileiras, e realizado um estágio inicial para 145 marinheiros namibianos no Grupamento de Patrulha Naval do Sudeste, no Rio de Janeiro (MD. MB 2011).

Em 2001, o governo de Fernando Henrique Cardoso assinou um novo Acordo de Cooperação Naval com o mesmo objetivo do anterior. Por ele, a 
Marinha Brasileira deveria assistir na organização do Serviço de Patrulha Marítima daquele país capaz de proteger seus interesses em suas águas internas, mar territorial e zona econômica exclusiva, fornecer embarcações e "assistir no planejamento e desenvolvimento de uma infra-estrutura apropriada à atracação e suporte logístico para tais embarcações". Os custos do treinamento e avaliação realizados no Brasil passaram a ser do governo da Namíbia e foi estabelecida a Missão Naval Brasileira na Namíbia (MRE 2001).

O acordo gerou uma série de ações decorrentes. Em 2004, a Corveta Purus, que havia sido "aposentada", foi transferida para a Namíbia sendo batizada naquele país de "NS Lt-Gen Dimo Hamaambo". No mesmo ano, foi acertado o fornecimento embarcações construídas no Brasil e, em 2006, a marinha brasileira criou Grupos de Apoio Técnico e enviou militares para a base de Walvis Bay. Em 2009, foi entregue o primeiro navio-patrulha construído no Brasil, batizado de "Brendan Sinbwaye" (Bastos 2011). Foram disponibilizadas vagas para os namibianos na Escola Naval, nos cursos de Aperfeiçoamento para Oficiais em Hidrografia e de Formação de Oficiais do Centro de Instrução Almirante Wandenkolk (CIAW), em cursos de especialização e de formação de marinheiros e soldados (MD. MB 2011).

As ações incluíram, ainda, a cooperação para a criação do Batalhão de Infantaria de Fuzileiros Navais namibiano e a realização de curso de formação de soldados; o desenvolvimento do Cerimonial da Marinha; a promoção de ações conjuntas de instrução e treinamento militar, exercícios militares conjuntos; e troca de informações e a colaboração em assuntos relacionados com sistemas, softwares e equipamentos, dentre outras (MD. MB 2011).

Em abril de 2010 a Missão Naval na Namíbia contava com cinco oficiais e onze praças (MD. MB, 2011; Prado 2009). No início daquele ano, ocorreu a formatura da primeira turma de Soldados Fuzileiros Navais da Namíbia formados pela Marinha do Brasil. Os soldados assumiram funções no "Marine Corps Battalion", futuro Batalhão de Infantaria de Fuzileiros Navais da Namíbia (Revista Forças Armadas 2011)

No âmbito do IBAS, em 2005, iniciou-se a realização das operações conjuntas denominadas "IBSAMAR", reunindo as marinhas do Brasil, Índia e África do Sul no litoral sul- africano, entre as cidades do Cabo e Simon's Town (MD. MB 2011). 
Em 2006, fruto do acordo de cooperação de 2003, as forças aéreas do Brasil e da África do Sul iniciaram o desenvolvimento de um projeto de míssil ar-ar de curto alcance, capaz de realizar manobras para atingir alvos durante o vôo e com sistema de detecção infravermelho, denominado A-Darter (Rangel $2010,48)$.

As escolas militares de formação e de altos estudos do Exército passaram a receber alunos dos países africanos, especialmente dos de língua portuguesa. Na Academia Militar das Agulhas Negras, em 2011, dos 42 cadetes estrangeiros que se encontravam matriculados, 27 eram de países da CPLP (dez de Angola, dez de Moçambique, dois de Cabo Verde, um de Guiné Bissau e quatro de São Tomé e Príncipe). A Escola de Comando e Estado-Maior do Exército (ECEME) tem um curso voltado para oficiais de nações amigas (ONA), que recebe em média 11 alunos por ano, dentre eles africanos. Em 1999 recebeu um angolano e em 2007 e 2011 oficiais da Nigéria ${ }^{4}$. Com o Gabão, a cooperação na área do ensino superior, abrangeu a formação de militares daquele país nas escolas de ensino superior da Marinha do Brasil e os dois governos demonstraram interesse em desenvolver a cooperação nos setores de formação de militares, treinamento para as operações de combate em ambiente tropical e na luta contra a bio-pirataria (MRE 2004b).

Em 2012 o ministro da Defesa da Mauritânia visitou o Brasil e na reunião com o Ministro Celso Amorim tratou da possibilidade de realização de exercício conjunto entre as duas marinhas (Murmel s/d). Há contatos estreitos com Cabo Verde para capacitação na área naval, de patrulha aérea e com o Exército na área de manutenção da ordem (Amorim 2012, 12).

Em 2013, o navio-patrulha Apa, construído pela empresa inglesa BAE Systems, em sua viajem do porto de Portsmouth no Reino Unido com destino ao Brasil, participou de missões na Mauritânia, Senegal, Angola e Namíbia (Murmel s.d.). O mesmo havia acontecido anteriormente na viagem inaugural do navio patrulha oceânico Amazonas, que realizou exercícios conjuntos e estreitou laços com as marinhas de Cabo Verde, Benin, Nigéria e São Tomé e

${ }^{4}$ Informações prestadas ao autor pelas divisões de ensino da Academia Militar das Agulhas Negras e pela Escola de Comando e Estado-Maior do Exército em 2011. 
Príncipe (Brasil, Amorim 2012, 12).

No âmbito da Força Aérea, a Academia da Força Aérea (AFA) formou pilotos de Angola, Moçambique e Guiné Bissau ${ }^{5}$ e o governo brasileiro acertou a venda de aviões de ataque leve Super Tucano para a Mauritânia e Burkina Faso (Amorim 2012).

A Comunidade dos Países de Língua Portuguesa (CPLP) se tornou um fórum internacional bastante atuante nas discussões no campo da segurança e defesa. Com base no documento jurídico denominado Protocolo de Cooperação da CPLP no Domínio da Defesa, foram criadas a Reunião de Ministros da Defesa Nacional, a Reunião dos Chefes de Estado- Maior de Defesa, e o Centro de Análise Estratégica (CAE) com a finalidade de discutir a profissionalização das forças armadas, a ética e a profissão militar ${ }^{6}$.

No âmbito da CPLP, foi criada a Operação Felino, em outubro de 2000, realizada anualmente em sistema de rodízio, com a participação de elementos dos exércitos de cada um dos países da Comunidade e com um Estado-Maior Multinacional. A operação é concebida no tema das missões de manutenção da paz e de ajuda humanitária (Brasil. EB s.d.).

O Brasil estabeleceu aditâncias militares junto às embaixadas brasileiras na África do Sul, Nigéria, Angola e em São Tomé e Príncipe, e a Agência Brasileira de Cooperação apoiou com bolsas de estudos a formação de quadros na área de segurança e defesa por meio da chamada "cooperação em conhecimento" (FKA 2009).

A ABC operacionalizou o memorando de entendimento assinado por ministérios da defesa do Brasil e de países da África para realização de cursos e treinamentos nas três forças armadas. Havia, ainda, a previsão do estabelecimento de uma acadêmica de polícia na Guiné-Bissau e treinamento contínuo de policiais a fim de auxiliar o país na reestruturação das forças de segurança pública (FKA 2009).

${ }^{5}$ Informação prestada pela Academia da Força Aérea (AFA) ao autor.

${ }^{6}$ Em 2010 foi realizada a 12 ${ }^{\mathrm{a}}$ Reunião de Ministros da Defesa Nacional da Comunidade dos Países de Língua Portuguesa (CPLP), em Brasília, e o $3^{\circ}$ Seminário do Centro de Análise Estratégica (CAE) da CPLP (Brasil, PR 2010; Brasil. MD 2006). 


\section{Conclusão}

O Brasil é parte do grupo de países desenvolvidos que não atingiram ainda os mesmos níveis sociais das potências, mas com capacidade econômica que pode impactar o sistema econômico internacional. Esses países, chamados emergentes, têm uma importância e uma liderança a nível regional e que aspiram a uma maior presença nos processo de decisões globais (Aguilar 2012).

A consciência brasileira de potência emergente foi se conformando a partir do final do século XX, por conta da situação do país como uma das maiores economias do mundo, possuidor do maior e mais diversificado parque industrial da América Latina, de imensos recursos minerais e naturais e de tecnologia avançada em algumas áreas, além da enorme capacidade de produção de alimentos.

A visão brasileira da ordem global contemporânea é de uma estrutura multipolar, assimétrica onde prevalece a incerteza e uma múltipla possibilidade de atores geradores de insegurança. Nesse contexto, o fortalecimento do multilateralismo seria a melhor opção para um país do porte do Brasil transitar no sistema, encarar a competição do comércio, responder às incertezas provocadas por atores estatais e não estatais que afetam a segurança e diminuir a assimetria com as grandes potências.

A opção pelo multilateralismo indicou a necessidade do fortalecimento das relações políticas bilaterais e a conformação de grupos com interesses comuns como IBAS e o BRICS (Brasil, Rússia, Índia, China e África do Sul). Assim, a cooperação Sul-Sul passou a fazer parte da busca pela autonomia da política externa brasileira, expressa na diversificação de parcerias e fóruns de atuação.

A busca pela autonomia foi executada de maneiras diferentes pelo governo brasileiro a partir da redemocratização do país, seja pelo afastamento dos países mais poderosos, adotada pelo governo Sarney, seja pela participação mais ativa nas instituições internacionais e o comprometimento a diversos tratados nas áreas de direitos humanos e de não proliferação nuclear, marca da política de Fernando Henrique Cardoso (Vigevani e Cepaluni 2012). No governo Lula e, atualmente, no de Dilma Roussef, buscou-se uma diversificação de parceiros que conduziu ao aprofundamento das relações com países emergentes 
como África do Sul, China, Índia e Rússia, e com os países africanos, especialmente os da costa ocidental e os de língua portuguesa.

A conformação de um mundo mais estável, na visão brasileira, se inicia com a estabilidade em nível regional. Dessa forma, a criação e o fortalecimento de arranjos na América do Sul garantiriam a paz no subcontinente e, em conseqüência, melhores condições de crescimento para a região como um todo. Na América do Sul, os maiores exemplos das ações nesse sentido foram a criação da União de Nações Sul-Americanas (UNASUL) e de seu Conselho SulAmericano de Defesa.

Sem inimigos declarados no seu entorno, as opções político-estratégicas desenhadas pela PDN e pela END elegeram como áreas de interesse estratégico a América do Sul, o Atlântico Sul, a costa ocidental da África e a Antártica. Dessas, sob o ponto de vista da defesa, a Amazônia e o Atlântico Sul são, hoje, as áreas prioritárias. Ou seja, determinaram a prioridade da política brasileira para a formatação de um processo de cooperação na América do Sul e com os países da costa ocidental da África.

$O$ planejamento de defesa se refere à possibilidade de intervenção de uma grande potência, ou uma coligação de potências, contra as quais o país teria dificuldades de fazer frente. Logo, os arranjos regionais em torno dessas áreas reforçariam o poder de dissuasão, dando um caráter coletivo à necessidade de defesa. É nessa direção que estão a UNASUL, a Organização do Tratado de Cooperação Amazônica e a ZOPACAS.

Dessa forma, a postura brasileira estaria relacionada com uma atitude preventiva de segurança, ou seja, mais baseada numa análise de possíveis mudanças no contexto internacional em longo prazo, e com a definição de um panorama mais favorável ao país no sistema internacional em curto prazo, que propriamente a necessidade de uma defesa imediata do território.

No caso do Atlântico Sul, a prioridade se deu por conta da visão brasileira da necessidade de proteger os recursos naturais da sua plataforma continental, que cresceu a partir da descoberta de jazidas de petróleo no pré-sal, e do comércio exterior brasileiro majoritariamente realizado pela via marítima do Atlântico. Ou seja, garantir a utilização sem constrangimentos deste espaço. Em conseqüência, surgiu a necessidade de ações que ultrapassassem as águas jurisdicionais ou de exploração econômica exclusiva brasileira, atingindo a costa atlântica da África. 
Assim, a diversificação de parcerias e o interesse estratégico conduziram ao o aprofundamento das relações e o estabelecimento de arranjos com os países da costa oeste africana, nas mais diversas áreas, incluindo a segurança e a defesa, como forma de consolidar a zona de paz nessa área.

Nesse contexto se dá a cooperação Sul-Sul. Além dos campos do comércio, desenvolvimento tecnológico, educação e concessão de créditos e financiamentos para a reconstrução nacional de Estados recém saídos de conflitos armados, como os casos de Angola, Moçambique e Guiné Bissau, dentre outros, uma série de acordos foram firmados no campo da segurança e defesa.

Ao mesmo tempo, houve uma conjunção de interesses de dupla via entre o Brasil e os africanos. Para esses, a prioridade dada pelo Brasil para o aprofundamento das relações, e a disponibilidade de recursos dela advinda, foi plenamente absorvida. Primeiro, porque programas, projetos e recursos para o desenvolvimento são sempre bem vindos, especialmente no caso dos países mais pobres ou com graves problemas estruturais, alguns em razão dos processos de violência que atravessaram nas últimas décadas. Segundo que, a aproximação foi facilitada pelos vínculos históricos como antigas colônias portuguesas ou por conta do tráfico de escravos. Terceiro, o Brasil se apresentou como uma opção melhor para o desenvolvimento de projetos de cooperação que com as exmetrópoles. Quarto, a cooperação brasileira representa uma ação que altera o eixo da dependência de ajuda, até então exclusiva dos países do Norte para os do Sul. Quinto, o conceito de cooperação praticado pelo Brasil implica na transferência de conhecimento e leva em consideração os interesses e prioridades dos países receptores, diferente da "cooperação impositiva" das relações NorteSul por conta da qual, normalmente, os países "doadores" indicam quais os projetos que desejam financiar, de acordo com seus interesses.

Esse parâmetro de transferência de conhecimento se mantém nos projetos e iniciativas na área de segurança com a América Latina e a África, regiões onde o conceito aplicado é o de segurança ampla, integrando políticas públicas e segurança alimentar ou ambiental, por exemplo.

Como a relação entre o Brasil e a maioria dos países africanos é assimétrica, a cooperação pouco acrescenta ao poder militar brasileiro, mas acrescenta muito ao poder dos que recebem os benefícios da relação. Por 
exemplo, a parceria firmada com o Brasil pela Namíbia não significa um aumento de poder militar do Brasil, mas tem permitido a constituição da Marinha daquele país, incluindo fuzileiros navais, e o aumento significativo da capacidade de garantir a soberania do Estado. Nesses casos, a cooperação, sob o ponto de vista estrito da segurança e defesa, se assemelha à assistência militar.

Dessa forma, os acordos indicam o uso do poder brasileiro em favor dos países menos desenvolvidos africanos. A disponibilização de meios e recursos para auxiliar o fortalecimento das forças armadas de alguns desses países, indicam o destaque que os governos brasileiros, a partir da década de 1990, deram para as questões com aquele continente, especialmente os países do Atlântico Sul.

Percebe-se que, no campo da segurança e defesa, não há a intenção de criar um grande mecanismo coletivo de defesa capaz de atuar para garantir a utilização sem constrangimentos ou ameaças do Atlântico Sul, mas sim uma cooperação para que os países africanos lindeiros do Atlântico possam construir forças armadas e de segurança pública capazes de garantir a paz interna e, consequentemente, regional. Assim, o Brasil estaria colaborando para um mundo mais seguro, ao mesmo tempo que conseguiria uma melhor articulação com diversos atores do sistema internacional. 


\section{REFERÊNCIAS}

Aguilar, Sérgio Luiz Cruz. 2010. Segurança e Defesa no Cone Sul: da rivalidade da Guerra Fria à cooperação atual. São Paulo: Porto de Idéias.

Aguilar, Sérgio. 2012. "Emerging powers, humanitarian assistance and foreign policy: the case of Brazil during the earthquake crisis in Haiti". International Journal of Humanities and Social Science 2: 93-101.

Amorim, Celso. 2012. "Defesa Nacional e Pensamento Estratégico Brasileiro". Conferência do Ministro da Defesa na abertura do Seminário Estratégias de Defesa Nacional. Brasília, 27 de novembro.

Arquivo Nacional. 1981a. Documento ACE 72494/89. SNI. Informação 481EMA (Secreta). Brasília, 26 de maio.

Arquivo Nacional. SNI. 1981b. "Apreciação n. 018/23/AC/81 (Secreto)". Brasília, 23 de junho.

Bastos, Expedito Carlos Stephani. 2011. “A Marinha do Brasil e sua projeção no Continente Africano." Juiz de Fora: UFJF. Disponível em: http://www.ecsbdefesa.com.br/defesa/fts/MBCA.pdf. Acesso: 30 jul. 2012.

Brasil. EB. s.d. "Militares das Forças Armadas participaram, no mês de março, do Exercício Felino, que ocorreu em Angola, na região de Cabo Ledo, na África". Disponível em: http://www.exercito.gov.br/c/journal/view_article_content?groupId= 13903\&articleId=499772\&version=1.0. Acesso em 20 março de 2013.

Brasil. PR. 2005. “Decreto 5.484. Aprova a Política de Defesa Nacional e dá outras providências". Brasília, 30 de junho.

Brasil. PR. 2010. "Ministros da Defesa de países de língua portuguesa se reúnem para discutir segurança". 08 de novembro. Disponível em: http:/www.brasil.gov.br/noticias/arquivos/2010/11/08/ministros-dadefesa-de-paises-de-lingua-portuguesa-se-reunem-para-discutirseguranca. Acesso em 20 de março de 2013.

Bueno, Clodoaldo; e Amado Cervo. 2008. História da Política Exterior do Brasil. Brasília: UnB.

FKA. 2009. "Relatório sobre a VI Conferência do Forte de Copacabana". Rio de Janeiro, 12/13 de novembro. Disponível em: 
http://www.kas.de/wf/doc/kas_18106-1522-5-30.pdf?091202194047.

Acesso em 21 março de 2013.

IBAS. 2012. Disponível em: http://www.ibsa-trilateral.org. Acesso em 21 de março de 2012.

MD. 2006. "Países de língua portuguesa discutem assuntos de defesa na GuinéBissau". Assessoria de Comunicação Social do MD. Disponível em: https://www.defesa.gov.br/index.php/ultimasnoticias/1148-25-04-06---paises-de-lingua-portuguesa-discutemassuntos-de-defesa-na-guine- bissau. Acesso em 20 de março de 2013. MD. 2008. "END - Estratégia Nacional de Defesa". Brasília.

MD. MB. 2011. "Centro de Comunicação Social da Marinha". Brasília. Disponível em:

http://www.mar.mil.br/menu_h/noticias/ccsm/cooperacao_Brasil-

Namibia.htm. Acesso em 16 de agosto de 2012.

MRE. 1994a. "Acordo de Cooperação entre o Governo da República da Namíbia e o Governo da República Federativa do Brasil". Windhoek, 04 de março.

MRE. 1994b. “Acordo sobre Cooperação Técnica no Domínio Militar entre o

Governo da República Federativa do Brasil e o Governo da República de Cabo Verde". Praia, 21 de dezembro.

MRE. 2001. “Acordo entre o Governo da República Federativa do Brasil e o Governo da República da Namíbia sobre Cooperação Naval". Windhoek, 03 de dezembro.

MRE. 2003. “Acordo entre o Governo da República Federativa do Brasil e o Governo da República da África do Sul sobre Cooperação em Assuntos Relativos à Defesa". Cidade do Cabo, 04 de junho.

MRE. 2004a. "Ajuste Complementar ao Acordo Geral de Cooperação entre o Governo da República Federativa do Brasil e o Governo da República de Moçambique no Âmbito da Segurança Pública". 31 de agosto.

MRE. 2004b. "Comunicado Conjunto da Visita de Estado de sua Excelência o

Presidente Luiz Inácio Lula da Silva à República Gabonesa". Libreville, 28 de julho.

MRE. 2006. “Acordo sobre Cooperação no Domínio da Defesa entre o Governo da República Federativa do Brasil e o Governo da República da Guiné-Bissau". Brasília, 06 de junho. 
MRE. 2009a. "Acordo entre o Governo da República Federativa do Brasil e o Governo da República da Namíbia sobre Cooperação no Domínio de Defesa". Windhoek, $1^{\circ}$ de junho.

MRE. 2009b. "Acordo sobre Cooperação entre o Governo da República

Federativa do Brasil e o Governo da República de Moçambique no

Domínio da Defesa". Maputo, 26 de março.

MRE. 2009c. "Ajuste Complementar ao Acordo Básico de Cooperação Técnica e Científica entre o Governo da República Federativa do Brasil e o Governo da República da Guiné-Bissau para Implementação do Projeto 'Centro de Formação das Forças de Segurança da GuinéBissau". Brasília, 07 de dezembro.

MRE. 2010a. "Acordo de Cooperação entre a República Federativa do Brasil e a República de Angola no Domínio da Defesa". Brasília, 23 de junho.

MRE. 2010b. "Acordo entre o Governo da República Federativa do Brasil e o Governo da República da Guiné Equatorial sobre Cooperação em Matéria de Defesa". Malabo, 05 de junho.

MRE. 2010c. "Acordo sobre Cooperação entre o Governo da República

Federativa do Brasil e o Governo da República Federal da Nigéria no

Domínio da Defesa". Brasília, 22 de julho.

MRE. 2010d. "Acordo sobre Cooperação entre o Governo da República

Federativa do Brasil e o Governo da República do Senegal no Domínio da Defesa". Brasília, 03 de agosto.

MRE. 2010e. "Declaração Conjunta sobre o Estabelecimento de Parceria

Estratégica entre a República Federativa do Brasil e o Governo da República de Angola". Brasília, 23 de junho.

MRE. ABC. 2011. Disponível em http://www.abc.gov.br. Acesso em 26 de maio de 2012.

Murmel, Nicholle. 2013. "NPaOc Apa inicia viagem ao Brasil com foco na cooperação com a África". Poder Naval. Disponível em: http://www.naval.com.br/blog/tag/marinha-dobrasil/\#ixzz2NjatQmUW. Acesso em 20 de março de 2013.

Nogueira, Ruy Nunes Pinto. 2010. "Cooperação Sul-Sul sob a perspectiva Brasileira". II Seminário de Alto Nivel sobre Política Externa. Brasília: FUNAG/IPRI. 
Prado, Alfredo. 2009. “Namíbia e Brasil apostam na cooperação militar e comercial". Revista África 21. Disponível em: http://www.africa21digital.com/noticia.kmf?cod $=8311085 \&$ canal $=40$ Acesso em 16 de agosto de 2011.

Rangel, Rogério. 2010. "Brasil e África do Sul: Desenvolvimento de novo míssil". Inovação em pauta 9: 48-49. Brasília: Finep.

Revista Forças Armadas. 2011. Disponível em: http://www.revistaforcasarmadas.com.br/revista/estrutura/marinhado-brasil-forma-primeira-turma-de-soldados-fuzileiros-navais-danamibia. Acesso em 16 de março de 2013.

SDM (Serviço de Documentação da Marinha). 1997. Relatório Anual da Marinha (Conf.). Brasília.

Silveira, Alexandre Prestes. 2002. "Cooperação Técnica: realidade e perspectivas no continente africano; um caso especial: cooperação com os PALOPS". In Relações Brasil - África: um colóquio, organizado por Pedro Motta Pinto Coelho e Hélio Magalhães de Mendonça, 285-292. Brasília: MRE.

Vigevani, Tullo; e Gabriel Cepaluni. 2012. Brazilian Foreign Policy in Changing Times: the quest for autonomy from Sarney to Lula. Maryland: Lexington Books. 


\section{Sérgio Luiz Cruz Aguilar}

\section{RESUMO}

A Cooperação Sul-Sul se conformou como um dos eixos da política externa brasileira, especialmente com a África. Além das áreas econômica, política e tecnológica, dentre outras, o governo brasileiro firmou uma série de acordos de cooperação no campo da segurança e defesa com diversos países africanos. $O$ trabalho aborda o sentido e o alcance das ações de cooperação SulSul entre o governo brasileiro e os países africanos, em especial os da África Atlântica, utilizando bibliografia que trata do assunto e fontes provenientes do Ministério de Relações Exteriores e do Ministério da Defesa.

PALAVRAS-CHAVE

Atlântico Sul; Brasil; Política Externa; Cooperação Sul-Sul; África. 